\title{
Mentalist evidentialism vindicated (and a super-blooper epistemic design problem for proper function justification)
}

\author{
Todd R. Long
}

\begin{abstract}
Michael Bergmann seeks to motivate his externalist, proper function theory of epistemic justification by providing three objections to the mentalism and mentalist evidentialism characteristic of nonexternalists such as Richard Feldman and Earl Conee. Bergmann argues that (i) mentalism is committed to the false thesis that justification depends on mental states; (ii) mentalism is committed to the false thesis that the epistemic fittingness of an epistemic input to a belief-forming process must be due to an essential feature of that input, and, relatedly, that mentalist evidentialism is committed to the false thesis that the epistemic fittingness of doxastic response $\mathrm{B}$ to evidence $\mathrm{E}$ is an essential property of $\mathrm{B}-\mathrm{E}$; and (iii) mentalist evidentialism is "unmotivated". I object to each argument. The argument for (i) begs the question. The argument for (ii) suffers from the fact that mentalist evidentialists are not committed to the consequences claimed for them; nevertheless, I show that there is, in the neighborhood, a substantive dispute concerning the nature of doxastic epistemic fittingness. That dispute involves what I call "Necessary Fittingness", the view that, necessarily, exactly one (at most) doxastic attitude (belief, or disbelief, or suspension of judgment) toward a proposition is epistemically fitting with respect to a person's total evidence at any time. Reflection on my superblooper epistemic design counterexamples to Bergmann's proper function theory reveals both the plausibility of Necessary Fittingness and a good reason to deny (iii). Mentalist evidentialism is thus vindicated against the objections.
\end{abstract}

Keywords Mentalism · Evidentialism - Epistemic fittingness · Proper function justification - Bergmann · Feldman - Conee 
In his book, Justification Without Awareness, Michael Bergmann (2006) ${ }^{1}$ argues that epistemic externalism about epistemic justification is theoretically preferable to any nonexternalism. ${ }^{2}$ Toward this end, he seeks to motivate our interest in his externalist, proper function theory of epistemic justification, by providing objections to leading nonexternalist epistemic theories. Notably, he makes three objections to what he calls $C F$-mentalism, which is essential not only to the evidentialist view of epistemic justification endorsed by Earl Conee and Richard Feldman (2004a, 2008) but also to the vast majority of nonexternalist theories of epistemic justification. Thus, Bergmann's objections to CF-mentalism threaten a broad swath of traditional epistemic theories.

I argue that none of the three objections provides good reason to deny CF-mentalism; thus, the objections provide no good reason to favor externalism over nonexternalism. Finally, I provide a counterexample to Bergmann's own externalist theory. Since reflection on the example also reveals substantial assets of CF-mentalism and versions of evidentialism, the combination of the example and my defense of CF-mentalism provides reason to prefer theories committed to CF-mentalism over Bergmann's externalist theory of justification.

\section{On Bergmann's first objection}

According to CF-mentalism (hereafter, mentalism), all the factors that contribute to epistemic justification (hereafter, justification) are in a person's mind. Conee and Feldman (2004b, p. 56) point out its two essential theses: (S) and (M):

S: "The justificatory status of a person's doxastic attitudes strongly supervenes on the person's occurrent and dispositional mental states, events, and conditions"; and,

M: "If any two possible individuals are exactly alike mentally, then they are alike justificationally, e.g., the same beliefs are justified for them to the same extent".

Bergmann's first objection to mentalism ${ }^{3}$ is as follows: ( $\mathrm{S} \& \mathrm{M}$ ) commits one to the mistaken thesis that

A: mental states are the only sorts of things that can be appropriate epistemic inputs to our belief-forming processes. (2006, p. 63)

\footnotetext{
${ }^{1}$ Chapters 7 and 8 are excellent additions to the literature concerning dialectical disputes between epistemic internalists and externalists. For critical discussion, see Rogers and Matheson (2009).

2 Although Bergmann (2006, pp. 55-7) claims that there are nonexternalist epistemic theories (including that of Conee and Feldman) that are neither internalist nor externalist, I'll use "nonexternalist" to mean any theory of epistemic justification that is not an externalist theory.

${ }^{3}$ Bergmann (2006, p. 48) converts Conee and Feldman's description of mentalism into a form he finds amenable to doxastic justification, which is his subject: "A belief's justification is a function solely of (i) which mental states the subject is in and (ii) which mental states of the subject the belief is based on. (i.e., if two possible subjects are exactly alike mentally and in terms of which of their mental states their beliefs are based on, then they are exactly alike justificationally)".
} 
Bergmann's reason for thinking that (A) is mistaken is his intuitive judgment about a type of case:

... many externalists will be inclined to think it is possible for God, if he exists, to reveal things to us (thereby giving us justified beliefs in the truths so revealed) by directly causing beliefs in us, without the causal intermediation of other mental states. My rejection of the mentalist answer ... [A] is based on this very line of thought. It just seems, intuitively, that such divinely caused beliefs could be justified. Hence, it seems intuitively that the mentalist answer ... [A] is mistaken.

The divine revelation example is a convenient one mainly because it is easy to make clear that there are no mental states that are mediating causes of the belief: God simply causes the belief in us directly. ${ }^{4}$ (2006, pp. 63-4)

I suppose that some epistemic externalists would agree with Bergmann's judgment but quite a few would not. Consider attempts by some externalists to deny that BonJour's Norman the Clairvoyant - who has beliefs produced by a reliable clairvoyant process-has justified clairvoyant beliefs ${ }^{5}$; and, consider the huge percentage of epistemic internalists (including some who think that religious beliefs can be epistemically justified) who would disagree. Bergmann (2006, p. 64) concedes that his objection to thesis (A) is persuasive only to non-mentalists; and, his intuitive judgment of the example (and another like it) ${ }^{6}$ is the only reason he offers against (A). Notably, that judgment is a minority judgment among epistemologists. Furthermore, from the perspective of what we might call the non-skeptical tradition-which is the perspective that Bergmann takes in his book-all the uncontroversial cases of justified belief involve mental-state inputs. So, if we are going to rely merely on intuitive judgments—as Bergmann does on

\footnotetext{
${ }^{4}$ Bergmann's commentary suggests that mentalism is committed to the following: necessarily, doxastically justified beliefs are caused by mental states. Not so: Feldman and Conee require basing but do not say that the basing must be causal. Nevertheless, as Kevin McCain pointed out to me, Bergmann's objection doesn't depend on the causal claim: the main dispute is whether mental states are necessary for justification.

${ }^{5}$ See BonJour (1985, p. 41). My point is not that such externalists will necessarily think that the two cases stand or fall together; rather, some externalists seem keen to place restrictions on which reliable causal processes are epistemically appropriate, and divine revelation (in the absence of anything mental such as a sense of the divine) is surely among the controversial ones.

Commenting on cases of reliable clairvoyants, Bergmann (2006, p. 141) says that, if we stipulate that their faculties are functioning properly, “... we have to admit that their clairvoyant beliefs are no more strange than our a priori or memory or perceptual beliefs". But, that is false, since clairvoyant beliefs are ones that just pop into a person's head helter-skelter, whereas the other kinds are typically related to common experiences (namely, seeing-the-truth experiences, memory experiences, and perceptual experiences, respectively).

${ }^{6}$ Bergmann's other example: "Imagine alien cognizers who form the belief that there is water nearby via a belief-forming process that bypasses their other mental states. Suppose, for example, that water in the environment of these aliens causes in them the belief that there is water nearby, without using any other mental states as intermediate causes of those beliefs. And suppose, furthermore, that these beliefs are not only reliably formed but also formed in accord with what counts as proper function for these cognizers" (2006, p. 64). As I point out in the text, Bergmann himself thinks that reliable belief formation is unnecessary for justification; and, if you think that the proper function mentioned in the example makes a difference, see my counterexample in Sect. 2.5.
} 
this issue-then the majority view of the example and intuitive judgments of uncontroversial cases provide modest reason to favor (A) over its denial. So, the objection to mentalism fails.

\section{On Bergmann's second objection}

Issues central to the second objection motivate the bulk of Bergmann's criticism of mentalism and mentalism-entailed evidentialism. Bergmann (2006, pp. 52, 63, 113) argues that endorsing mentalism commits one to the mistaken thesis that

B: the epistemic fittingness of any input to our belief-forming processes must be due to an essential feature (rather than a contingent feature) of that input.

His big-picture objection to thesis (B): Bergmann's own externalist, proper function theory of justification (hereafter, proper function justification) preserves the theoretical assets of mentalism and Feldman-Conee-style evidentialism illustrated by certain examples, ${ }^{7}$ but, unlike mentalism, proper function justification allows the epistemic appropriateness of an input to be a contingent feature of it; thus, he argues, mentalism has no theoretical advantage over proper function justification; and, since proper function justification - which entails the denial of (B) - jibes better with some intuitive epistemic evaluations with respect to some other examples than does mentalism, proper function justification is theoretically preferable.

2.1 Why mentalists are not committed to (B) as characterized

Before considering those other examples, it would be helpful to consider what Bergmann is charging mentalists as holding. I take it that Bergmann has us consider thesis (B) in the interest of isolating the simplest feature of what it is that he wants to criticize about mentalism. But, there is trouble here, for mentalists are not committed to (B) as Bergmann characterizes it. We will need to do some sorting to discover just how it is that the examples Bergmann uses reveal what he finds objectionable about mentalism. To make sense of the examples we will later evaluate, we need to understand how Bergmann's criticisms rely on some claims about design plans for belief-formation.

Bergmann draws our attention to two possible "design plans", where a design plan is the complete description of the natural way of functioning for a cognizer. ${ }^{8}$ According to "the human design plan", cognizers function properly when they form belief B1: there is a smallish hard round object in my hand, as an unlearned causal response to having "main evidence" ME1: tactile sensations of the type you experience when you grab a billiard ball. According to "design plan B", cognizers function properly when they form belief B1 as an unlearned causal response to

\footnotetext{
${ }^{7}$ That is, proper function justification implies the same, correct epistemic evaluations with respect to examples that Feldman and Conee use to illustrate the merits of their view.

${ }^{8}$ In this section I summarize relevant parts of Bergmann (2006, Chap. 5).
} 
having "main evidence" ME2: olfactory sensations of the type you experience when you smell a meadow full of flowers. Bergmann claims that the two processes are on an epistemic par. They exhibit, he thinks, ways in which the epistemic fittingness of evidential inputs to a belief-forming process can vary with respect to cognizers' design plans: although the human design plan makes it epistemically fitting for $u s$ to form B1 on the basis of ME1 (but not on the basis of ME2), it could be that some nonhuman design plan makes it epistemically fitting for some nonhuman persons to form B1 on the basis of ME2 (but not on the basis of ME1); thus, he says, thesis (B) is false.

The story and the moral Bergmann draws from it are supposed to be problematic for mentalists, but how so? We are invited to think that mentalism commits one to the view that ME1, but not ME2, can be an epistemically fitting input to a beliefforming process that results in B1; in other words, mentalism implies that ME1, but not ME2, can be a justifier for B1. But, mentalism does not imply this. Indeed, Conee and Feldman - the very mentalists that Bergmann is criticizing-have an excellent reason internal to their view of epistemic justification for denying thesis (B) as Bergmann characterizes it, and yet they remain consistent mentalists. This reason has to do with their view that it is one's total evidence that matters for epistemic justification. For instance, take the sensory experience that one might consider to be an input to a belief-forming process resulting in an external world belief such as B1. Conee and Feldman (2008) explicitly deny that sensory experience alone can justify any external world belief. On their view of justification, it is something about the total evidence (including background evidence, concept acquisition, etc.) that people typically have that justifies external world beliefs. Their particular theory, which they describe as an "explanatory coherence view of evidential support" (hereafter, the EC view), is that what justifies such a belief involves "the best available explanation of one's evidence", where that explanation consists of "a body of propositions about the world and one's place in it that make the best sense of the existence of one's evidence" (Conee and Feldman 2008, p. 98). Describing the EC view as a non-traditional version of coherentism, they say, "The coherence that justifies holds among propositions that assert the existence of the non-doxastic states that constitute one's ultimate evidence and propositions that offer an optimal available explanation of the existence of that evidence" (Conee and Feldman 2008, p. 98). Perceptual experiences, then, can contribute to the justification of an external world proposition for a person when that proposition is part of the best explanation available to the person of that person's experiences. Accordingly, they might acknowledge that a sensory experience counts as an "epistemic input" in a typical case of justified external world belief (so long as "an epistemic input" means "something that contributes to justification"), since a sensory experience is part of the total evidence one has in such a case. But, they are not committed to the view that any particular sensory "input" is, in isolation, epistemically fitting.

Consider how these points bear on Bergmann's criticism of mentalism. Bergmann apparently thinks that mentalism entails that, if there is a world (such as what we take to be ours) in which ME1 justifies B1, then there is no possible world in which ME2 justifies B1 (and vice versa). As I have noted, mentalism does 
not entail that there is any world in which ME1 (or ME2) in isolation justifies B1. Nevertheless, consider the possibilities on the EC view. The view does not preclude ME2's contributing to the justification of B1 for a person. Suppose a world in which a person $\mathrm{S}$ grows up in a community of folk whose testimony concerning the relation between ME2 and the content of B1 always confirms the view that ME2 indicates the presence of a hard round object in one's hand, and suppose that S's own ME2 experiences always confirm the relation. In such a case, ME2 could contribute to the justification of B1 for S, since ME2 could be part of the set of experiences that B1 best explains for S. Thus, the EC view, and thus mentalism, does not entail that ME2 cannot be an epistemic input to a belief-forming process that results in B1's being justified for a person; that is, mentalism does not entail that ME2 cannot be epistemically fitting. On the contrary, it could be.

There are two complicating issues worth discussing. First, we should be careful in saying that the EC view allows for either ME1 or ME2 to be an epistemically fitting input to a process resulting in the formation of B1. The EC view would characterize either ME1 or ME2 as an epistemically fitting input only if it were suitably related to other epistemic inputs of the cognizer. Still, there is a straightforward sense in which the EC view is consistent with Bergmann's claim that either ME1 or ME2 could be epistemically fitting and thus be a justifier of B1. So, mentalism is consistent with a human-design-planned cognizer's forming B1 justifiedly upon experiencing ME1, and mentalism is consistent with a non-humandesign-planned cognizer's forming B1 justifiedly upon experiencing ME2. Thus, whatever thesis (B) actually expresses, Bergmann's commentary on (B) gives us no reason to think that mentalists are committed to a false thesis.

Second, Bergmann says that B1 can be justified for a person even though it is an unlearned causal response to either ME1 or ME2. The fact that this external world belief is unlearned should give us pause. Typical justified external world beliefs are surely learned doxastic responses. I cannot think of any uncontroversial case of an unlearned doxastic attitude that is justified. So, I doubt that we have any familiar cases of the sort on which to rely in support of Bergmann's conclusion about the case. In the end, I do not think that Bergmann's main criticism of mentalism with respect to thesis (B) and Necessity (discussed below) turns on this issue of whether unlearned external world beliefs can be justified, but if it does, we should note two things: (i) Bergmann's contention about unlearned doxastic responses is no better supported than was his criticism of mentalism with respect to thesis (A); that is, the uncontroversial cases of justified external world belief count against Bergmann's contention that unlearned external world beliefs can be justified; and, (ii) mentalism

itself is neutral on the issue of whether unlearned doxastic responses can be justified. Thus, we would do well to look elsewhere to find a relevant dispute.

\subsection{Bergmann on "Necessity"}

Before dismissing any Bergmannian objection along this line, we should consider Bergmann's objections to what he calls Necessity, for he thinks that mentalists' commitment to thesis (B) is closely related to what he takes to be their commitment to Necessity. 
Necessity: the [epistemic] fittingness of doxastic response B to evidence E is an essential property of that response to that evidence. (2006, p. 112)

Bergmann (2006, p. 113) treats Necessity as a thesis that paradigm evidentialists, such as Feldman and Conee, are committed to, a thesis that he claims also commits them to thesis (B). ${ }^{9}$ Like thesis (B), what Necessity says is somewhat obscure. Let us try to understand Bergmann's point about it by first considering the examples Bergmann uses to illustrate his criticism of Necessity.

Case III: Due to cognitive malfunction caused by a radiation overdose, a human comes to have the tendency to form B1 in response to ME2. The same overdose also prevents her from ever noticing anything wrong with forming this belief this way. Since ME2 isn't a reliable indicator of the truth of B1, the result is that B1 is not reliably formed.

Case IV: A nonhuman cognizer with "design" plan B forms B1 in response to "olfactory" sensation ME2. This belief is a reliably formed belief produced by that cognizer's properly functioning faculties in an appropriate environment for the operation of those faculties.

Case V: A nonhuman cognizer with "design" plan B forms B1 in response to ME2. This belief is a properly functioning unlearned doxastic response for such a creature to ME2. However, since this cognizer is a demon victim whose perceptual beliefs are all artificially produced, ME2 is not produced by actual contact with a billiard ball (nothing like such contact occurs for this cognizer). The result is that B1 is not reliably formed.

Case VI: Due to cognitive malfunction caused by a radiation overdose, a nonhuman cognizer with "design" plan B comes to have the tendency to form B1 in response to "tactile" sensation ME1. The same overdose also prevents her from ever noticing anything wrong with forming this belief in this way. Since in this environment (which is an appropriate one for this cognizer) ME1 isn't a reliable indicator of the truth of B1, the result is that B1 is not reliably formed. (2006, pp. 137-8).

Bergmann (2006, p. 139) says that reliabilist theories get case V wrong, whereas nonexternalists endorsing Necessity get cases IV, V, and VI wrong. His argument depends on his intuitive judgments about the cases:

In both case IV and case V, B1 seems to be justified. For in those cases ..., B1 is a properly functioning and fitting unlearned response to the main evidence despite the fact that, in case $\mathrm{V}$, the belief is formed in an unreliable way. And since case VI is like case III in that B1 is a malfunctioning and unfitting unlearned response to the subject's main evidence, B1 seems to be as unjustified in case VI as it is in case III. (2006, p. 138)

\footnotetext{
${ }^{9}$ Bergmann (2006, p. 113) says, "Evidentialists, by endorsing Necessity, give an affirmative answer to (B)".
} 


\subsection{The trouble with "Necessity"}

Are mentalists committed to the conclusions about cases IV, V, and VI that Bergmann charges them with? Using the EC view as our mentalist exemplar, note that the cases are under described for our purposes. In cases IV and V we are not told whether ME2 is part of the respective cognizer's total evidence such that the proposition believed is part of the best explanation available to the cognizer. If it is, then the EC view, and thus mentalism, is consistent with Bergmann's claim that B1 is justified. In case VI, we are not told whether ME1 is part of the cognizer's total evidence such that the proposition believed is part of the best explanation available to the cognizer. If it is not, then the $\mathrm{EC}$ view, and thus mentalism, is consistent with Bergmann's claim that B1 is unjustified.

Another problem with Bergmann's commentary on Necessity is that the examples used for the purpose of criticizing mentalism and evidentialism rely on cases of unlearned doxastic responses. Case $\mathrm{V}$ is explicitly a case of an unlearned doxastic response, and Bergmann's subsequent commentary indicates that the same goes in cases IV and VI. Again, I do not think that Bergmann's main criticism of mentalist evidentialism turns on this issue, but, if it does, my criticism of Bergmann's objection to thesis (B) applies to these cases as well.

\subsection{The substantive conflict}

We have, so far forth, failed to reveal a problem for mentalism that Bergmann's examples are supposed to provide. To understand the crucial issue, we need to consider further details concerning "epistemic fittingness", which appears in both thesis (B) and Necessity. One initial problem with taking Bergmann's objection to mentalism as turning on Necessity is that mentalism itself does not entail Necessity. ${ }^{10}$ This is because mentalism does not imply anything substantive about evidence. Nevertheless, since Bergmann treats Necessity as a feature of leading evidentialist views such as Feldman and Conee's, we may consider how Bergmann's view of epistemic fittingness conflicts with features of such views. We may appreciate the substantive conflict by considering some theses in the neighborhood of Necessity that are less obscure and which are accepted by the evidentialists under consideration:

Uniqueness: At any time $\mathrm{t}$ and for any person $\mathrm{S}$ with any particular total evidence with respect to any proposition p, exactly one (at most) doxastic attitude (belief, or disbelief, or suspension of judgment) toward $\mathrm{p}$ is epistemically justified for $\mathrm{S}$ at t. ${ }^{11}$

\footnotetext{
${ }^{10}$ I do not claim that Bergmann takes mentalism to entail Necessity. He explicitly discusses Necessity as a thesis that evidentialists who are mentalists are committed to. I make the textual point for clarity's sake.

${ }^{11}$ I think that many evidentialists implicitly endorse Uniqueness. For explicit discussions, see Feldman (2007, p. 205), who endorses Uniqueness; see White (2005), who argues against various anti-Uniqueness views; and see Christensen (2007), who offers some reasons in favor of what he calls "Rational Uniqueness"- "the view that there is a unique maximally epistemically rational response to any given evidential situation"- saying that he finds the view to be "quite attractive".
} 
Uniqueness is about justification. Bergmann's idea is that what confers justification just is whatever makes a doxastic attitude epistemically fitting. So, the relevant thesis about epistemic fittingness for the relevant evidentialists would be the following:

Necessary Fittingness: At any time $t$ and for any person $S$ with any particular total evidence TE with respect to any proposition p, exactly one (at most) doxastic attitude (belief, or disbelief, or suspension of judgment) toward $\mathrm{p}$ is epistemically fitting with respect to TE for $\mathrm{S}$ at $\mathrm{t}$.

As we have noted, Bergmann thinks that facts about epistemic fittingness, and thus justification, are contingent on facts about design plans. On his view, if there are two cognizers who possess exactly the same total evidence with respect to $\mathrm{p}$ at time $\mathrm{t}$, one can justifiedly believe $\mathrm{p}$ at $\mathrm{t}$ and the other can justifiedly disbelieve $\mathrm{p}$ at $\mathrm{t}$, and what explains the difference in justification is a difference in design plan. Such a view is plainly inconsistent with Uniqueness and Necessary Fittingness. Thus, we have now located a clear dispute between Bergmann and the evidentialists whose views Bergmann criticizes.

Before discussing the dispute, it may be helpful to distinguish and clarify some components of the evidentialist views I have been discussing. Mentalism-the conjunction of (S) and (M) - was introduced by Feldman and Conee as a means of distinguishing internalist views of justification from externalist views. The $E C$ view-Feldman and Conee's explanatory coherence view of evidential support-is a specific evidentialist view consistent with mentalism. But, mentalism does not entail the EC view; indeed, mentalism does not even entail evidentialism (the view that justification is entirely a matter of one's evidence) ${ }^{12}$; and, since views about what constitutes one's evidence can vary, evidentialism does not even entail mentalism. Although Bergmann is not careful in distinguishing mentalism from evidentialism, he is right to locate a serious dispute between paradigm evidentialists and himself concerning facts about doxastic epistemic fittingness; for, those evidentialists (hereafter, mentalist evidentialists) are committed to Uniqueness and Necessary Fittingness, which Bergmann denies. For ease of presentation, I will use the term mentalist evidentialism to refer to the conjunction of mentalism, Uniqueness, Necessary Fittingness, and Necessary Support (discussed below).

The question before us is this: what reason does Bergmann offer for denying Necessity (and, by extension, Uniqueness and Necessary Fittingness)? Apart from his commentary on the examples we have considered, the only reason Bergmann proffers is his intuitive judgment that his own view of doxastic fittingness just is epistemic fittingness. His central idea is this: a doxastic response is an epistemically fitting response (i.e., the kind that makes for justified belief) only if it is a properly functioning response; and, it is a properly functioning response only if it is consistent with its design plan.

What should we think of the proposal? No doubt it provides a way to understand doxastic fittingness of some sort based on proper function. In cases IV and V, for instance, the cognizers form beliefs just as they were designed to form them, and

\footnotetext{
$\overline{12}$ For instance, responsible belief theorists can count as mentalists without counting as evidentialists.
} 
that indicates that those beliefs possess some form of doxastic fittingness with respect to a design plan; but, it does not follow that the doxastic fittingness illustrated is epistemic fittingness; indeed, what constitutes epistemic fittingness is the very point at issue. So, if he is to provide good reason-for anyone who does not share his view of epistemic fittingness - to deny mentalist evidentialism on the basis of denying Necessary Fittingness, then he must provide a good non-partisan, independent reason, to believe that his account of doxastic fittingness just is epistemic fittingness, rather than an account consistent with Necessary Fittingness.

We might look for such a reason in Bergmann's commentary on his own theory of justification $\left(\mathrm{J}_{\mathrm{PF}}\right)$ :

$\mathbf{J}_{\mathbf{P F}}$ : S's belief B is justified iff (i) S does not take B to be defeated and (ii) the cognitive faculties producing B are (a) functioning properly, (b) truth-aimed and (c) reliable in the environments for which they were "designed". (2006, p. 133)

Bergmann (2006, pp. 134-7) says that he includes clauses (ii) (b) and (ii) (c) in order to ensure that his analysis exemplifies epistemic fittingness. He requires-as do mentalist evidentialists - that epistemic fittingness is "objective" in the sense that one's mere thinking that one's belief caused by a cognitive faculty is epistemically fitting is insufficient for actual epistemic fittingness. The idea behind Bergmann's specific view is that his conditions exemplify epistemic fittingness because they have something to do with an objective connection between sources of justified belief and truth, which is an epistemic good. This idea has some plausibility, but it does not show that Bergmann's view of epistemic fittingness is correct, since evidentialists can also plausibly say that epistemic fittingness has something to do with an objective connection between sources of justification and truth. For instance, Feldman and Conee (2004, p. 93) - (and many other nonexternalists) — think that only a well-founded belief that $\mathrm{p}$ (i.e., a belief based on what necessarily provides propositional justification with respect to p) exhibits doxastic epistemic fittingness. As Conee (2004) has argued, it is plausible that (1) propositional justification is evidence of the truth of a proposition and (2) the "truth connection" between justification and truth is the relation of evidential support. "Well-foundedness" just adds that a belief is had on the basis of justifiers of the proposition believed.

More can be said on behalf of mentalist evidentialists' commitment to an objective connection between sources of justified belief and truth. A theoretical asset of mentalist evidentialism is that it is supported by the plausibility of what I call Necessary Support:

Necessary Support: Under all possible conditions, any particular total body of evidence TE with respect to any proposition $\mathrm{p}$ is such that one, and only one, of the following is true: (i) TE supports the truth of p, or (ii) TE supports the truth of not-p, or (iii) TE supports the truth of $p$ to the same extent that TE supports the truth of not-p.

Given mentalist evidentialists' commitment to mentalism, Necessary Support, Uniqueness, and Necessary Fittingness, the connection between sources of justified 
belief and truth implied by mentalist evidentialism is "objective" in Bergmann's sense. It does not help Bergmann's case to point out that mentalist evidentialism does not entail that justified beliefs are reliably produced, since the same goes for Bergmann's theory. ${ }^{13}$

Does it help Bergmann's case that his theory entails that justified beliefs are reliably produced in the environment(s) for which they were designed, whereas typical evidentialist views do not? I presume that a number of those who think that some kind of reliability is required for justification will think that this point counts in Bergmann's favor, whereas most traditionalists about justification will doubt it. Suppose, though, for the sake of argument, we grant that the point counts in Bergmann's favor. ${ }^{14}$ Does it follow that we now have a good, non-question begging reason to deny Necessary Fittingness? No. This is because some views of justification that entail Necessary Fittingness have additional theoretical assets of their own, assets that are at least as intuitively compelling, from a non-partisan perspective, as the one about environmental reliability. I shall illustrate these assets by means of an example that figures in my super-blooper epistemic design objection to $\mathrm{J}_{\mathrm{PF}}$.

\subsection{The super-blooper epistemic design objection to $\mathrm{J}_{\mathrm{PF}}$}

The super-blooper epistemic design objection utilizes an example ${ }^{15}$ : Suppose that there is a powerful, knowledgeable Humean "infant deity" $\mathrm{Z}$ who has created cognizers that are approximately as intelligent as humans. ${ }^{16} \mathrm{Z}$ has designed his cognizers reliably to believe truths in various circumstances of the environment in which he has placed them. Accordingly, the "Z-design plan" calls for Z's created cognizers to form belief $\mathbf{B} 2$ (there exists a powerful personal creator, and there is a family of trolls living deep under my planet's surface), as an inference from their belief that $\mathbf{p}$ (I'm experiencing olfactory sensations $O$ ) — which are of the type that ordinary humans have when they smell a meadow full of flowers-and their belief that $\mathbf{q}$ (if $p$, then there exists a powerful personal creator, and there is a family of trolls living deep under my planet's surface). ${ }^{17}$ The cognizers are designed to believe $\mathrm{p}$ and $\mathrm{q}$ upon physical contact with another Z-designed cognizer, and they are designed not to notice that they have no reason to believe that appreciating the content of q's antecedent provides a good reason to believe q's consequent

\footnotetext{
${ }^{13}$ Bergmann (2006, p. 134) explicitly acknowledges this, treating the point as a theoretical asset of his theory, since it allows for the correct results concerning the new evil demon problem, whereas reliabilist theories do not.

${ }^{14}$ As I explain in Sect. 3, there is a good reason to deny that this point counts in Bergmann's favor.

15 This example has roughly the same structure as one in Long (forthcoming), but here it is used for a different purpose.

16 In Part V of his commentary, David Hume (1993) suggests that this much of my imaginary creationand-design story is consistent with what we know of our own world and its human cognizers.

${ }^{17}$ For those who want a story: Although $\mathrm{Z}$ is an immature deity whose created world falls far short of a best possible world, Z, having recently been infuriated by the deceptions of his older siblings, has developed a passion for honesty and truth about some matters; and, due to his youthful vanity, $\mathrm{Z}$ has designed those cognizers such that their happiness depends in part on their believing that $\mathrm{Z}$ exists.
} 
(in contrast with the fact that they are designed to appreciate, say, that Rex is running unaided gives them reason to believe that Rex has legs); accordingly, they don't take themselves to have a defeater for q (just as it is with p). Also, being designed to keep all these beliefs to themselves, the cognizers have no reason to believe that there is a family of trolls living under their planet's surface (i.e., it does not seem to them that they have sensory experience of trolls, or that they have heard testimony about actual trolls, etc.). ${ }^{18}$ Suppose further that $\mathrm{p}, \mathrm{q}$, and the proposition expressed by B2 are all true in the world envisioned whenever a cognizer in that world believes those propositions. Having frequent contact with others, these cognizers frequently engage in a belief-forming inference from ( $p$ and $q$ ) to the content of B2, forming B2 on the basis of that inference. ${ }^{19}$ The cognitive faculties producing those beliefs are successfully aimed at truth (in Bergmann's sense), for those faculties are likely to produce true beliefs when operating in the environment for which they were designed.

Suppose that one Z-designed cognizer, Mork, has just formed B2 as described and that Mork's relevant cognitive faculties are functioning as designed, are truthaimed, are reliable in the environments for which they were designed, and Mork does not take B2 to be defeated. $\mathrm{J}_{\mathrm{PF}}$ implies that Mork's belief B2, as well as his belief that $\mathrm{p}$ and his belief that $\mathrm{q}$, are epistemically justified. According to Bergmann, then, all of these beliefs exhibit doxastic epistemic fittingness.

However, consultation with my intuitions (and, I predict, most of yours) about the case produces a very confident belief that Mork's forming B2 in the way indicated does not exhibit epistemic fittingness, even if it exhibits some kind of doxastic fittingness. I daresay that many externalists will agree, for there is good reason to do so. Mork's method is intellectually poor: it is an irrational, objectively bad way to reason, even if he cannot help it and even if it gets him onto the truth. ${ }^{20}$ Mentalist evidentialism easily preserves this judgment, in part because it is committed to Necessary Support, which provides support for Necessary Fittingness.

This point seems even more compelling when we add to the story. Suppose that Spork-another cognizer under the Z-design plan-comes to realize that she has reason to think that the truth of q's consequent is not connected to the truth of q's antecedent, and, as a result, Spork disbelieves that q. On the basis of this realization, Spork suspends judgment on the content of B2. It seems that Spork is reasoning well, and this suggests that her disbelief that $\mathrm{q}$ and her suspension of judgment on the content of B2 are justified. I think Bergmann would say that the correct evaluation of these attitudes depends on a contingent fact concerning whether

\footnotetext{
18 For those who want a story: $\mathrm{Z}$ has a reason for the cognizers to believe in the trolls' existence: such beliefs are designed to have a salutary role in their unconscious dreams, providing some psychological aid in their struggles against the hardship and suffering that $\mathrm{Z}$ predicts they will endure due to details of the particular world $\mathrm{Z}$ has designed and created.

19 Other scenarios serve the same point. Simpler Alternative Story (drop the conjunction): Under the conditions described, the cognizers are designed to engage in an inference from $p$ to the content of B2. Weirder Alternative Story (invalid reasoning): The cognizers are designed to engage in an invalid inference, say, if $p$ then $q ; r$ (I'm a cognizer); thus, the content of B2.

20 And perhaps things are even worse in the Weirder Alternative Story (see footnote 19).
} 
Spork's realization is part of the defeater system part of the Z-design plan. ${ }^{21}$ So, let us suppose that Spork's realization is not consistent with the Z-design plan's defeater system. Accordingly, $\mathrm{J}_{\mathrm{PF}}$ implies that Spork's disbelief that $\mathrm{q}$ is unjustified. ${ }^{22}$ So, $\mathrm{J}_{\mathrm{PF}}$ is mistaken: Spork reasons well, and this suggests that all of her discussed doxastic attitudes are justified; but, she does not believe as designed. ${ }^{23}$

Although I do not claim to have demonstrated that $\mathrm{J}_{\mathrm{PF}}$ is false, reflection on the examples gives us a reason to doubt $\mathrm{J}_{\mathrm{PF}}$. What drives our sense that we have such a reason? What else could it be-at the level of abstraction with which we are here concerned-than our sense that Necessary Support and Necessary Fittingness are true? The views preserve our sense that there are essentially good ways and essentially bad ways of engaging in epistemically rational inquiry; the good ways do not become epistemically bad if one's design plan fails to sanction them, and the bad ways do not become epistemically good if one's design plan happens to sanction them. Mentalist evidentialism easily preserves these claims.

The super-blooper epistemic design examples reveal another asset of mentalist evidentialism: it has the resources to secure an intimate relation between epistemic justification and epistemic rationality, a relation that has been a hallmark of traditional views of epistemic justification going back at least to the Socrates of Plato's Meno. ${ }^{24}$ Typical evidentialist views of justification have it that one must have evidence indicating the truth of a proposition in order for one to be justified in believing that proposition; and, one's having evidence indicating the truth of a proposition very plausibly constitutes one's having a reason to believe that proposition; hence, typical evidentialist views imply that there is an intimate relation between epistemic justification and epistemic rationality.

$\mathrm{J}_{\mathrm{PF}}$, however, does not imply that there is an intimate relation between epistemic justification and epistemic rationality. Consider the doxastic attitudes of Mork, for example. On $\mathrm{J}_{\mathrm{PF}}$, Mork's belief that $\mathrm{q}$ and his belief $\mathrm{B} 2$ are epistemically justified, but those beliefs are not epistemically rational. For his beliefs to be epistemically rational, Mork would have to have a reason with respect to the propositions believed. ${ }^{25}$ But, he lacks a reason to believe that $q$. And, although Mork's belief B2, being the result of an inference, can be said to have been formed on the basis of

${ }^{21}$ Bergmann (2006, p. 170) says that "defeater systems" are "similar to belief-forming systems, except that the result of their operation is belief loss not belief production".

${ }^{22}$ Since $\mathrm{J}_{\mathrm{PF}}$ is about belief (and does not mention suspension of judgment), $\mathrm{J}_{\mathrm{PF}}$ seems to be silent on the justificatory status of Spork's suspending judgment on the content of B2.

${ }^{23}$ Reflection on the fact that Bergmann builds the defeater system into the relevant design plan for any cognizer prompts the thought that there is little hope of adding a clause to Bergmann's account of epistemic defeat that will both count Spork's belief as justified and avoid entailing Necessary Fittingness or an evidentialist-friendly account of epistemic defeat.

${ }^{24}$ According to Plato's Meno [97e], Socrates says that the difference between true belief and knowledge is "an account of the reason why" (Plato, 2002, p. 90).

${ }^{25}$ Here I rely on straightforward definitions of "rational": "having reason or understanding" (Webster); "reason, reasonableness" (Princeton WordNet); "of or based on reasoning or reason" (Oxford English Reference). In recent years, some have used "rational" or "epistemically rational" in ways that have nothing at all to do with one's having reason, but such uses strike me as untoward stretches of the word. In any case, take my point in the text to be that typical evidentialist views of epistemic justification preserve a tight connection between justified belief and reasonable belief. 
reasoning, B2 is surely epistemically irrational, since Mork literally has no reason to believe the content of B2. ${ }^{26}$ Now consider the doxastic attitudes of Spork. They are epistemically rational, but according to $\mathrm{J}_{\mathrm{PF}}$, unjustified. ${ }^{27}$ Thus, $\mathrm{J}_{\mathrm{PF}}$ does not have the resources to secure an intimate relation between justification and rationality. ${ }^{28}$

So, on the one hand we have $\mathrm{J}_{\mathrm{PF}}$, which entails the denial of Necessary Fittingness, since it implies that the epistemic fittingness (or unfittingness) of an agent's doxastic response to the agent's evidence can be due to a contingent feature (i.e., the "design" plan, which could vary across possible cognizers); and, on the other we have mentalist evidentialism, which is committed to mentalism, Necessary Support, Uniqueness, and Necessary Fittingness. Each view, we might think from a non-partisan perspective, has some theoretical assets. What reason does Bergmann offer for adjudicating the views? He offers his controversial judgments about the cases we have considered, judgments that are supported by nothing more than the claim that his view of epistemic fittingness - which is revisionary and questionbegging - is correct. Hence, Bergmann has not provided a reason, for anyone who does not share his view of epistemic fittingness, to deny Necessary Fittingness. I conclude that Bergmann's objections directed to thesis (B) and Necessity fail to reveal a problem for mentalism.

\section{On Bergmann's third objection}

Bergmann's third objection to mentalism is that it is "unmotivated" (2006, pp. 59-61). He argues for the claim by responding to what he takes to be two proposed motivations for mentalism in work by Feldman and Conee. One is a defense by Feldman of thesis (B). But, for the reasons discussed above, Feldman has not defended (B) or Necessity (as Bergmann characterizes it); so, we should consider Bergmann's discussion of Feldman's argument as applied to mentalist evidentialism. Accordingly, the truth of mentalist evidentialism helps to explain why mentalism can-but externalist theories such as reliabilism cannot—support the intuitively compelling view that demon-worlders have the same justified beliefs as their introspectively identical non-demon-world twins. Bergmann's response is that $\mathrm{J}_{\mathrm{PF}}$ does just as well as mentalism on this score, without being committed to reliabilism; hence, Feldman's argument provides no good reason to prefer mentalism over Bergmann's externalism.

The trouble is that $\mathrm{J}_{\mathrm{PF}}$ does not do just as well as mentalism with respect to the new evil demon problem. Intuitively, our introspectively identical twins in demon worlds have the same justified beliefs as us despite the fact that they are radically and systematically deceived. $\mathrm{J}_{\mathrm{PF}}$ plausibly gets the right results only in demon worlds in which the cognizers are under roughly the same design plan that we are

\footnotetext{
${ }^{26}$ Mork may feel impelled to believe the content of B2, but a feeling of impulsion is not itself a truthindicating reason. For discussion of this point, see Long 2010: 384-386, Conee 1998, and Conee and Feldman 2004b: 64-67.

${ }^{27}$ Spork's suspension of judgment on the content of B2 is an exception, since $\mathrm{J}_{\mathrm{PF}}$ says nothing about suspension of judgment.

${ }^{28}$ For further discussion of this point, see Long (forthcoming).
} 
under; it gets the wrong results in demon worlds where cognizers have been designed by the demon, for in those worlds, the processes producing the beliefs of our mental twins are not reliable in the environments for which they were designed; thus, $\mathrm{J}_{\mathrm{PF}}$ has a severely restricted application in preserving intuitions with respect to the new evil demon problem. ${ }^{29}$ Mentalism implies no such restriction on demon worlds. This point provides a significant motivation for mentalism.

The other proposed motivation that Bergmann discusses is Conee and Feldman's claim that mentalism provides the best explanation of our intuitive judgments about certain example pairs. Bergmann's response (2006, pp. 59-60) has two parts: (1) The example pairs Conee and Feldman use in support of their mentalist view are handled easily by $\mathrm{J}_{\mathrm{PF}}{ }^{30}$; and (2) there are additional examples which are better handled by $\mathrm{J}_{\mathrm{PF}}$ than by mentalism. But, even if $\mathrm{J}_{\mathrm{PF}}$ handles Conee and Feldman's cases as well as mentalism does, once we appreciate the points I have made we are in a position to see that Bergmann's additional examples do not provide any reason to deny mentalism for anyone who does not already accept Bergmann's view of epistemic fittingness: after all, the additional examples Bergmann offers to illustrate the superiority of his theory are the very examples we have considered.

After the dialectical dust settles, all that remains for Bergmann are his intuitive judgments about his examples. But, those judgments are deeply controversial $^{31}$; and, if all we have to go on are epistemologists' intuitions about the cases, they provide modest reason to accept mentalism and mentalist evidentialism (and, thus, to "motivate" them) over $\mathrm{J}_{\mathrm{PF}}$, since, from the perspective of the nonskeptical tradition from which Bergmann is working, every uncontroversial case of justified belief is consistent with the discussed features of mentalism and mentalist evidentialism. But, we now have more to go on, namely, the super-blooper epistemic design objection. Reflection on the example it employs provides additional reason to prefer mentalism and mentalist evidentialism.

Acknowledgments I thank Earl Conee, Richard Feldman, Jonathan Matheson, Kevin McCain, Jason Rogers, and William Rowley for helpful comments.

\section{References}

Bergmann, M. (2006). Justification without awareness: a defense of epistemic externalism. Oxford: Clarendon Press.

BonJour, L. (1985). The structure of empirical knowledge. Cambridge, MA: Harvard University Press. Christensen, D. (2007). Epistemology of disagreement: the good news. Philosophical Review, 116(2), $187-217$.

Conee, E. (1998). Seeing the truth. Philosophy and Phenomenological Research, 58, 847-857.

\footnotetext{
${ }^{29}$ As Bergmann (2006, p. 136) himself points out, on his view it is only "in some evil demon cases [that] the subject's beliefs are objectively justified.... What is true in most demon cases is that the subject's beliefs are subjectively justified". Our topic is what Bergmann calls "objective justification".

30 These example pairs are paraphrased in Bergmann (2006, pp. 139-40). The actual examples appear in Conee and Feldman (2004b, pp. 59-61).

${ }^{31}$ For additional worries that Bergmann's arguments rely too heavily on his intuitive judgments, see Hetherington (2007).
} 
Conee, E. (2004). The truth connection. In E. Conee \& R. Feldman (Eds.), Evidentialism: essays in epistemology (pp. 242-254). Oxford: Clarendon Press.

Conee, E., \& Feldman, R. (2004a). Evidentialism: essays in epistemology. Oxford: Clarendon Press.

Conee, E., \& Feldman, R. (2004b). Internalism defended. In E. Conee \& R. Feldman (Eds.), Evidentialism: essays in epistemology (pp. 53-80). Oxford: Clarendon Press.

Conee, E., \& Feldman, R. (2008). Evidence. In Q. Smith (Ed.), Epistemology: new essays (pp. 83-104). Oxford: Oxford University Press.

Feldman, R. (2007). Reasonable religious disagreements. In L. Antony (Ed.), Philosophers without gods (pp. 194-214). Oxford: Oxford University Press.

Feldman, R., \& Conee, E. (2004). Evidentialism. In E. Conee \& R. Feldman (Eds.), Evidentialism: essays in epistemology (pp. 83-101). Oxford: Clarendon Press.

Hetherington, S. (2007). Review of M. Bergmann's Justification without awareness: a defense of epistemic externalism. Mind, 116(464), 1088-1092.

Hume, D. (1993). Dialogues concerning natural religion. In A. Flew (Ed.), Writings on religion (pp. 183-292). La Salle, IL: Open Court.

Long, T. R. (2010). A proper de jure objection to the epistemic rationality of religious belief. Religious Studies, 46(3), 375-394.

Long, T. R. (forthcoming). Proper function justification and epistemic rationality. Southwest Philosophy Review.

Plato, (2002). Meno. In G. M. A. Grube (Ed.), Five dialogues. 2nd ed, (trans.) (pp. 58-92). Indianapolis, IN: Hackett.

Rogers, J., Matheson, J. (2009). Bergmann's dilemma: exit strategies for internalists. Philosophical Studies. doi: 10.1007/s11098-009-9460-0.

White, R. (2005). Epistemic permissiveness. In J. Hawthorne (Ed.), Philosophical perspectives: epistemology, 19 (pp. 445-459). Malden, MA: Blackwell. 